\title{
Assessment of the Knowledge and Practice of Nurses about Family Planning Counseling in Health Care Centers - Lattakia
}

\author{
Manal Rajab Al-Shawakh ${ }^{1, *}$, Nisreen Mohie Mostafa ${ }^{2}$, Linda Mohamed Saleh ${ }^{3}$ \\ ${ }^{1}$ Faculty of Nursing, Tishreen University, Lattakia, Syria \\ ${ }^{2}$ Department of Gynecological Nursing and Woman Health, Faculty of Nursing, Tishreen University, Lattakia, Syria \\ ${ }^{3}$ Community Health Nursing Department, Faculty of Nursing, Tishreen University, Lattakia, Syria
}

Received April 30, 2020 ; Revised May 27, 2020; Accepted June 23, 2020

Copyright $(2020$ by authors, all rights reserved. Authors agree that this article remains permanently open access under the terms of the Creative Commons Attribution License 4.0 International License

\begin{abstract}
Objective: This study aimed to assess the knowledge and practice of nurses about family planning counseling in health care centers- Lattakia city to identify gaps in nurses' information and practice. Design: This was a purposive analytical study using a structured questionnaire that assessed the demographic characteristics of the nurses, and the nurses' knowledge about family planning counseling, and observation checklist to assess the practice of nurses during family planning counseling sessions. The data were analyzed with the SPSS software version stata 6.0. Settings: This study was conducted at the reproductive health clinics of health care centers, Lattakia. Subjects/participants: All nurses who work in reproductive health clinics in the time of the study $(n=29)$. Results: The nurses who had a good and medium level of knowledge constituted $(62.07 \%, 37.93 \%)$ respectively, none of them had low level. The nurses who had a low and medium level of practice constituted (62.07\%, 37.93\%) respectively, none of them had a good level. Knowledge and practice about family planning counseling were statically connected. A significant statistical relation was found $(\mathrm{P}=0.015)$. Conclusion: The nurses had a good level of knowledge and a low level of practice about family planning counseling, so they need training programs and a guide on family planning counseling.
\end{abstract}

Keywords Knowledge, Practice, Family Planning Counseling, Nurses, Health Care Centers

\section{Introduction}

The high population growth serves to increase the poverty rate, and a positive association found between family size, poverty incidence and severity. Therefore, the negative impacts of poverty rise on household savings, labor force participation, and income of parents, as well as on the human capital investment in children [1].

Family planning and birth control are the main goals of governments worldwide for population growth control and appropriate contraceptive use is a measure to realize these goals [2]. The link between family planning and population growth, health, and economic growth is well documented. Thus, where the rate of family planning use is low, human development indices are low as well [3].

Family planning reduces health risks to women and gives them more control over their reproductive lives. With better health and greater control over their lives, women can take advantage of education, employment and civil opportunities. In addition, it is not difficult for parents to dress and feed their children if they can limit their family size. The expenses that they need to care for a small-sized family will be less, so they can save more and be self-sufficed. With regard to social services, both the government and family invest less if the family and population size are small. This can help save essential resources and thereby contributes to the economic growth of the nation as a whole [4].

WHO defines family planning as "a way of thinking and living that is adopted voluntarily, upon the basis of knowledge, attitude and responsible decisions by individuals and couples, in order to promote the health and welfare of family groups, thus effectively contribute to the social development of a country" [5]. WHO recommends that all women seeking abortion or post-abortion care services should be provided with family planning information, counseling and methods and that most methods can be initiated immediately following surgical or medical abortion procedures [6]. 
Counseling is face to face communication process in which one person helps another, couple, family, or a group to identify their needs, make decisions, and proper choices. Family planning counseling is a conversation between two individuals or more to understand specific issues related to reproductive and sexual health needs, also to clarify their emotions and find a way to deal with them [7].

Contraceptive counseling that emphasizes effective and safe contraception plays a significant role in women's health. Moreover, providing contraceptive counseling is considered essential to women's health because it encourages women and couples to choose a method that is congruent with their needs and helps them use that method correctly. Providing contraceptive counseling has a positive impact on women's health by reducing unwanted pregnancies and providing proper gaps between births. Spacing gives mothers time to regain their health and recover from the psychological stress and physiological changes of previous pregnancies [8,9].

Family planning counseling is done through many stages which include; establishing rapport and assessing client's needs and concerns, provide information to address client's needs and concerns, help the client make an informed decision or address a problem, and help carry out client's decision [10]. Family planning counseling has six elements, GATHER model is a useful memory aid to help us to remember the basic steps in the counseling process and to add structure to a complex activity. The following are elements of successful counseling: Greet the client in a friendly, helpful, and respectful manner, Ask the client about family planning needs, concerns, and previous use, Tell the client about different contraceptive options and methods, Help the client to make decisions about the choice of method she or he prefers, Explain to the client how to use the method, Return schedule and carry out return visit and follow-up of client [11]. REDA is another model, which is more open and flexible; Rapport is developed between counselor and client, Explore the problem, situation and options for change, Decide on the best option, Act on the decision [12].

In Uganda, a study conducted by USAID and Population council found that health workers' knowledge was very low about family planning methods before and after providing the interventions "yellow star program" which aimed to improve family planning services [13]. Adinma [2010] study found that $72,8 \%$ of health care workers had good knowledge about family planning counseling, but only $69,1 \%$ gave the counseling [14]. While Karvande [2018] found a lack of nurses' knowledge about family planning counseling [15]. In Ethiopia, a study of Abebaw [2019] found that $87,3 \%$ of health care workers had good knowledge about family planning counseling, and 90,2\% of them performance counseling regularly [16]. In addition, the Study of Kebalepile [2001] concluded that almost all nurses have good knowledge, and poor practice of family planning counseling [17].
In Jordan, Kamhawi [2013] studied the effects of the program "consult and choose" and found that it served to increase the nurses' performance for family planning counseling [18], and the study of Nasr and Hassan [2016] in Egypt, concluded that majority of nurses (83.97\%) had a satisfactory performance for family planning counseling, except "Tell stage" of counseling, just the third of nurses performed this stage [19]. Also, Tseganeh [2005] founded that $82,9 \%$ of nurses performed family planning counseling, but failed to follow the steps of counseling [20].

There are many reasons stand behind inadequate family planning counseling performed by the nurses such as nurses were not interested, time shortage, some of them did not have an adequate level of knowledge, lack of professional training on counseling protocols, and long duration without continuous training on family planning counseling serve to delay nurses' knowledge and practices about family planning counseling [20, 21]. Also, the heavy workload, crowded and noise in clinics are reasons of nurses were not provided [22].

The role of nursing is expanded and strengthened as experts with profession fill the void in women's health care. Women can now receive a total assessment, planned treatment, education, counseling and support from the nurse. Additional training and professional developments within the nursing profession generally, mean that nurses now undertake many of the extended clinical roles previously performed by doctors. This increasing autonomy means that many families planning clinics now are run by "nurse only", where no doctor is present $[23,24]$.

The decrease in population growth is one of the most important issues in Syria today due to the impact of the war on health, economic, educational and other fields. Despite the high rate of contraceptive methods use in Syria, the challenge is still very big, because of high percent of women still depend on traditional contraceptive methods with high failure rates, and that produces more unwanted pregnancies. Given the importance of the role played by family planning counseling in reducing population growth rates by reducing the incidence of unwanted pregnancy through an increasing rate of modern and effective contraceptive methods use by both partners equally responsible for fertility, and the impact this on the health of mothers, their children and society as a whole. Given the importance of nurses' role in providing counseling, it is necessary to assess the knowledge and practice of nurses on family planning counseling in order to obtain a basic database that helps in raising the quality of family planning counseling by improving the same.

\section{Materials and Methods}

This study was a purposive analytical study conducted at the reproductive health clinics of health care centers, Lattakia. It covered two months from December 2018 to February 2019. There are 14 health care centers in Lattakia 
city, the total number of nurses in reproductive health clinics was 32, the sample comprised all nurses who work in reproductive health clinics at the time of study after the pilot study sample was excluded from the sample $(n=29)$. The data were collected via a researcher- administered questionnaire, an observation checklist, that was developed by the researchers to elicit demographics and nurses' knowledge about family planning counseling and practice of nurses about family planning counseling, after careful literature review. The questionnaire (first tool) was pretested to nurses, and the researcher observed nurses during counseling sessions to collect data to the observation checklist (second tool). The data entry was analyzed using the Statistical Package for Social Sciences Stata (version 6.0). Variables were analyzed with descriptive statistics, showing the frequencies and percentages. Bi-variate analyses amongst the level of knowledge and level of practice were done with chi-square statistic. All p-values less than 0.05 were considered statistically significant. Approval for the study was obtained from the Research and Ethics Committee of Tishreen University, Lattakia.

\section{Results}

\subsection{Demographic Characteristics}

Table 1 shows the nurses' demographic characteristics; the nurses aged older than 45 years constituted $51.72 \%$, $41.38 \%$ aged $31-45$ years, and $6.9 \%$ aged younger than 30 years.

The nurses who are in relation (married) constituted $89.66 \%$, and single nurses are $10.34 \%$. Nurses who studied nursing after elementary school constituted $72.41 \%$, and $20.69 \%$ studied nursing after secondary school, 6.9\% studied nursing institutes. None of them studied the faculty of nursing.

The nurses who had experienced more than 5 years in reproductive clinics constituted $86.21 \%$, and the percent of the nurses who had experienced less than 1 year and from 1 to 5 years in reproductive clinics were equal $6.9 \%$.

Table 1. Distribution of the nurses according to their demographic characteristics

\begin{tabular}{|c|c|c|}
\hline Demographic characteristics: & $\begin{array}{c}\text { No } \\
(n=29)\end{array}$ & $\%$ \\
\hline \multicolumn{3}{|l|}{ Age: } \\
\hline - $\quad \leq 30$ years & 2 & 6.9 \\
\hline - $\quad 31-45$ years & 12 & 41.38 \\
\hline - $\quad>45$ years & 15 & 51.72 \\
\hline \multicolumn{3}{|l|}{ Marital status: } \\
\hline - $\quad$ Single & 3 & 10.34 \\
\hline - $\quad$ In relation (married) & 26 & 89.66 \\
\hline \multicolumn{3}{|l|}{ Level of education: } \\
\hline - $\quad$ Nursing school after elementary & 21 & 72.41 \\
\hline - $\quad$ Nursing school after secondary & 6 & 20.69 \\
\hline - $\quad$ Institute of nursing & 2 & 6.9 \\
\hline - $\quad$ Faculty of nursing & $\mathbf{0}$ & $\mathbf{0}$ \\
\hline \multicolumn{3}{|l|}{ Experience in reproductive clinics: } \\
\hline - $\quad$ Less than 1 year & 2 & 6.9 \\
\hline - 1 to 5 years & 2 & 6.9 \\
\hline - $\quad>5$ years & 25 & 86.21 \\
\hline
\end{tabular}

\subsection{Level of Knowledge}

Table 2 shows the nurses' level of knowledge; the nurses who had a good level constituted $62.07 \%, 37.93 \%$ had a medium level. None of them had a low level.

Table 2. Distribution of the nurses according to the level of knowledge about family planning counseling

\begin{tabular}{|c|c|c|c|c|c|c|}
\hline \multirow{2}{*}{ Knowledge } & \multicolumn{4}{|c|}{ Knowledge level } & \multicolumn{2}{c|}{ Medium } \\
\cline { 2 - 7 } & \multicolumn{2}{|c|}{ Low } & \multicolumn{2}{c|}{ Mod } \\
\cline { 2 - 7 } & $\mathrm{N}$ & $\%$ & $\mathrm{~N}$ & $\%$ & $\mathrm{~N}$ & $\%$ \\
\hline Concept of family planning counseling & 0 & 0.00 & 6 & 20.69 & 23 & 79.31 \\
\hline Communication skills & 0 & 0.00 & 9 & 31.03 & 23 & 79.31 \\
\hline Contraceptive methods & 0 & 0.00 & 16 & 55.17 & 13 & 44.83 \\
\hline Counseling process & 2 & 6.90 & 17 & 58.62 & 10 & 34.48 \\
\hline Total degree of knowledge & 0 & 0 & 11 & 37.93 & 18 & 62.07 \\
\hline
\end{tabular}

Table 3. Distribution of the nurses according to the level of practice about family planning counseling

\begin{tabular}{|c|c|c|c|c|c|c|}
\hline \multirow{2}{*}{ Practice } & \multicolumn{3}{|c|}{ Level of practice } & \multicolumn{2}{c|}{ Good } \\
\cline { 2 - 7 } & \multicolumn{2}{|c|}{ Low } & \multicolumn{2}{c|}{ Medium } & $\mathrm{N}$ & $\%$ \\
\cline { 2 - 7 } & $\mathrm{N}$ & $\%$ & $\mathrm{~N}$ & $\%$ & 8 & 27.59 \\
\hline Communication skills & 12 & 41.38 & 9 & 31.03 & 0 & 0.0 \\
\hline Counseling process & 19 & 65.52 & 10 & 34.48 & 0 & 0.0 \\
\hline Total degree of practice & 18 & 62.07 & 11 & 37.93 & 0 & \\
\hline
\end{tabular}




\subsection{Level of Practice:}

Table 3 shows the nurses' level of practice; the nurses who had low level constituted $62.07 \%, 37.93 \%$ had medium level. None of them had a good level of practice.

\subsection{Relation between Level of Knowledge and Level of Practice:}

Table 4 displays the relation between the nurses' level of knowledge and their level of practice; It is obvious that both levels are related. A significant statistical relation was found $(\mathrm{P}=0.015)$.

\subsection{Relation between Demographic Characteristics and Level of Knowledge}

Table 5 shows the relation between the nurses' demographic characteristics and their level of knowledge; It is obvious that the nurses' level of knowledge is not related to any of their demographic characteristics (age, marital status, level of education, experience in reproductive clinics). There was no significant statistical relation. $\mathrm{P}$ values were $(\mathrm{P}=0.431 ; \mathrm{P}=0.644 ; \mathrm{P}=0.066 ; \mathrm{P}=$ 0.132 ) respectively.

Table 4. Relation between level of knowledge and level of practice about family planning counseling

\begin{tabular}{|c|c|c|c|c|c|c|c|c|}
\hline \multirow{3}{*}{\multicolumn{2}{|c|}{ Relation }} & \multicolumn{6}{|c|}{ Level of knowledge } & \multirow{3}{*}{$P$ value } \\
\hline & & \multicolumn{2}{|c|}{ Low } & \multicolumn{2}{|c|}{ Medium } & \multicolumn{2}{|c|}{ Good } & \\
\hline & & $\mathrm{N}$ & $\%$ & $\mathrm{~N}$ & $\%$ & $\mathrm{~N}$ & $\%$ & \\
\hline \multirow{3}{*}{ Level of practice } & Low & 0 & 0 & 10 & 90.91 & 8 & 44.44 & \multirow{3}{*}{$0.015^{*}$} \\
\hline & Medium & 0 & 0 & 1 & 9.09 & 10 & 55.56 & \\
\hline & Good & 0 & 0 & 0 & 0 & 0 & 0 & \\
\hline
\end{tabular}

Table 5. Relation between demographic characteristics and the level of knowledge

\begin{tabular}{|c|c|c|c|c|c|c|c|}
\hline \multirow{3}{*}{ Demographic characteristics: } & \multicolumn{6}{|c|}{ Level of knowledge } & \multirow{3}{*}{$P$ value } \\
\hline & \multicolumn{2}{|c|}{ Low } & \multicolumn{2}{|c|}{ Medium } & \multicolumn{2}{|c|}{ Good } & \\
\hline & $\mathrm{N}$ & $\%$ & $\mathrm{~N}$ & $\%$ & $\mathrm{~N}$ & $\%$ & \\
\hline \multicolumn{7}{|l|}{ Age: } & \multirow{4}{*}{0.431} \\
\hline - $\quad \leq 30$ years & 0 & 0 & 0 & 0 & 2 & 11.11 & \\
\hline - $\quad 31-45$ years & 0 & 0 & 6 & 54.55 & 6 & 33.33 & \\
\hline - $\quad>45$ years & 0 & 0 & 5 & 45.45 & 10 & 55.56 & \\
\hline Marital status: & & & & & & & \multirow{3}{*}{0.644} \\
\hline - $\quad$ Single & 0 & 0 & 1 & 9.09 & 2 & 11.11 & \\
\hline - $\quad$ In relation (married) & 0 & 0 & 10 & 90.91 & 16 & 88.89 & \\
\hline \multicolumn{7}{|l|}{ - $\quad$ Level of education: } & \multirow{5}{*}{0.066} \\
\hline $\begin{array}{ll}- & \begin{array}{l}\text { Nursing school after } \\
\text { elementary }\end{array} \\
\end{array}$ & 0 & 0 & 10 & 90.91 & 11 & 61.11 & \\
\hline $\begin{array}{ll} & \text { Nursing school after } \\
\text { secondary }\end{array}$ & 0 & 0 & 0 & 0 & 6 & 33.33 & \\
\hline - $\quad$ Institute of nursing & 0 & 0 & 1 & 9.09 & 1 & 5.56 & \\
\hline - $\quad$ Faculty of nursing & 0 & 0 & 0 & 0 & 0 & 0 & \\
\hline \multicolumn{7}{|l|}{ Experience in reproductive clinics: } & \multirow{4}{*}{0.132} \\
\hline - Less than 1 year & 0 & 0 & 2 & 18.18 & 0 & 0 & \\
\hline - 1 to 5 years & 0 & 0 & 0 & 0 & 2 & 11.11 & \\
\hline - $\quad>5$ years & 0 & 0 & 9 & 81.82 & 16 & 88.89 & \\
\hline
\end{tabular}


Table 6. Relation between demographic characteristics and level of practice

\begin{tabular}{|c|c|c|c|c|c|c|c|}
\hline \multirow{3}{*}{ Demographic characteristics: } & \multicolumn{6}{|c|}{ Level of practice } & \multirow{3}{*}{$P$ value } \\
\hline & \multicolumn{2}{|c|}{ Low } & \multicolumn{2}{|c|}{ Medium } & \multicolumn{2}{|c|}{ Good } & \\
\hline & $\mathrm{N}$ & $\%$ & $\mathrm{~N}$ & $\%$ & $\mathrm{~N}$ & $\%$ & \\
\hline \multicolumn{7}{|l|}{ Age: } & \multirow{4}{*}{0.278} \\
\hline - $\quad \leq 30$ years & 0 & 0 & 2 & 18.18 & 0 & 0 & \\
\hline - $\quad 31-45$ years & 8 & 44.44 & 4 & 36.36 & 0 & 0 & \\
\hline - $\quad>45$ years & 10 & 55.56 & 5 & 45.45 & 0 & 0 & \\
\hline \multicolumn{7}{|l|}{ Marital status: } & \multirow{3}{*}{0.316} \\
\hline - $\quad$ Single & 1 & 5.56 & 2 & 18.18 & 0 & 0 & \\
\hline - $\quad$ In relation (married) & 17 & 94.44 & 9 & 81.82 & 0 & 0 & \\
\hline \multicolumn{7}{|l|}{ Level of education: } & \multirow{5}{*}{0.281} \\
\hline - $\quad$ Nursing school after elementary & 14 & 77.78 & 7 & 63.64 & 0 & 0 & \\
\hline - $\quad$ Nursing school after secondary & 2 & 11.11 & 4 & 36.36 & 0 & 0 & \\
\hline - $\quad$ Institute of nursing & 2 & 11.11 & 0 & 0 & 0 & 0 & \\
\hline - $\quad$ Faculty of nursing & 0 & 0 & 0 & 0 & 0 & 0 & \\
\hline \multicolumn{7}{|l|}{ Experience in reproductive clinics: } & \multirow{4}{*}{0.132} \\
\hline - $\quad$ Less than 1 year & 2 & 11.11 & 0 & 0 & 0 & 0 & \\
\hline - 1 to 5 years & 0 & 0 & 2 & 18.18 & 0 & 0 & \\
\hline - $\quad>5$ years & 16 & 88.89 & 9 & 81.82 & 0 & 0 & \\
\hline
\end{tabular}

\subsection{Relation between Demographic Characteristics and Level of Practice}

Table 6 shows the relation between the nurses' demographic characteristics and their level of practice; It is obvious that the nurses' level of practice is not related to any of their demographic characteristics (age, marital status, level of education, experience in reproductive clinics). There was no significant statistical relation. $\mathrm{P}$ values were $(\mathrm{P}=0.278 ; \mathrm{P}=0.316 ; \mathrm{P}=0.281 ; \mathrm{P}=0.132)$ respectively.

\section{Discussion}

Statically, the Syrian population will be 28.66 million in 2025, which will be a huge challenge to the government's planning and achievement levels. Large efforts were done to elevate rates of contraceptive use from $46.6 \%$ in 2001 to $53.9 \%$ in 2009 [25]. Despite the elevation in contraceptive use rate, the challenge was still huge, because a large percent of women depend on traditional contraceptive methods, with high rates of failure because of both partners which cause more unwanted pregnancies [26]. So, this study was carried out to assess the nurses' knowledge and practice about family planning counseling in health centers - Lattakia.

Results of the present study reveal that almost two-thirds of nurses have a good level of knowledge about family planning counseling (table 2). This result is concordant with studies of Adinma [2010], Nigeria; Abebaw [2019], Ethiopia; Kebalepile [2001], Northern Botswana [14, 16, 17]. But disagree with Karvande [2018], India, which reveals that nurses have a low level of knowledge about family planning counseling [15]. Also, Tseganeh [2005], Ethiopia, which revealed that nurses had an inadequate level of knowledge about family planning counseling [20]. The result of the present study due to that most of the nurses in our study had experienced for many years of work in reproductive clinics, and the majority of them were auxiliary nurses whose education and training focus on a special field like a reproductive health nursing.

Saka [2012] found that health care workers had inadequate training in family planning counseling [21]. In the present study, lack of training may explain the result that about two-thirds of nurses have a low level of practice about family planning counseling (table 3). This result is supported by Kebalepile [2001] who stated that nurses had a low level of practice about family planning counseling [17]. Also, Shahidzadeh-Mahani [2008] revealed that nurses' practice in family planning counseling was low [22]. On the other hand, this result disagrees with that of Abebaw [2019], Ethiopia; who revealed that the majority of nurses had good practice in family planning counseling [16]. In addition, Adinma [2010] found that more than two-thirds of nurses have good practice in family planning counseling. She also found that there was no significant statistical relation between the level of knowledge and the level of practice [14], this result disagrees with that of the 
present study which indicates significant statistical relation ( $p$ value $=0.015$ ) between the level of knowledge and the level of practice (table 4). The result of the present study due to that most of the nurses failed to follow a specific model in performing family planning counseling. Moreover, Atuahene [2016]. stated that health care workers failed to follow standard protocols of family planning counseling [27].

Results of the present study reveal that there is no significant statistical relation between nurses' demographic characteristics (age, marital status, level of education, experience in reproductive clinics) and their level of knowledge (table 5).

Rahmati [2017] revealed that there was significant statistical relation between nurses' level of education and their level of practice in family planning counseling, whereas the auxiliary nurses had a higher level of practice of family planning counseling more than bachelor degree nurses [28].

Shahidzadeh-Mahani [2008] found that there was significant statistical relation between nurses' level of education and their level of practice in family planning counseling [22]. These studies disagree with the result of the present study, which reveals that there is no significant statistical relation between nurses' level of education and their level of practice in family planning counseling (table 6).

Shahidzadeh-Mahani [2008] revealed that there was significant statistical relation between nurses' experience in reproductive health clinics and their level of practice in family planning counseling [22]. But it disagrees with the result of the present study, which reveals that there was no significant statistical relation between nurses' experience in reproductive clinics and their level of practice in family planning counseling (table 6). Besides, the results of the present study revealed that there is no significant statistical relation between nurses' age or marital status and their level of practice in family planning counseling (table 6).

\section{Conclusions}

Under the results of the present study, researchers may conclude that the nurses had a good level of knowledge and low level of practice about family planning counseling, and there is a relationship between the level of knowledge and the level of practice about family planning counseling, so we recommend preparing and achieving training programs about family planning counseling, distributing guide and posters about family planning counseling for nurses, and develop, evaluate, and implicate a guide about family planning counseling.

\section{Acknowledgments}

This study was supported by the faculty of nursing,
Tishreen University, Lattakia, Syria. We would like to thank all the nurses who so willingly participated in this study, as well as all the experts who evaluated the tools of the study.

\section{REFERENCES}

[1] J. Nansseu, E. Nchinda, JC. Katte, F. Nchagnouot, G. Nguetsa. Assessing the knowledge, attitude and practice of family planning among women living in the Mbouda health district, Cameroon. Reproductive Health, Vol.12, No.92, 1-7, 2015.

[2] UNFPA. State of World Population Report in a World of 7 Billion, UNFPA, New York 10158 USA, 2012.

[3] S. Joshi, P. Schultz. Family planning and women's and children's health: long-term consequences of an outreach program in Matlab. Bangladesh Demography, Vol. 50, No. 1, 149-180, 2013.

[4] Ethiopian Federal Ministry of Health. Family Planning: Blended Learning Module for the Health Extension Programme, Ethiopian Federal Ministry of Health, Addis Ababa, 2011.

[5] M. Omishakin. Knowledge, Attitude, and Practice of Family Planning among Healthcare Providers in two Selected Health Centers in Osogbo Local Government, Osun State. Women's Health \& Gynecology, Vol.1, No.2, 1-4, 2015.

[6] World Health Organization. Safe abortion: technical and policy guidance for health systems (2nd ed.), World Health Organization, Geneva, 2012.

[7] F. Terki, U. Malhotra. Medical and service delivery guidelines for sexual and reproductive health services (3rd ed.), International Planned Parenthood Federation, London, 2004.

[8] J. Stanback, M. Steiner, L. Dorflinger, J. Solo, W. Cates. WHO Tiered-Effectiveness Counseling Is Rights-Based Family Planning. Global Health: Science and Practice, Vol.3, No.3, 352- 357, 2015.

[9] A. Lee. Improving contraceptive compliance through an evidence-based educational program. Evidence Based Women's Health Journal, Vol.4, No.1, 40-6, 2014.

[10] M. Festin. Elements of Family Planning Counselling and Reproductive Rights. Training Course in Sexual and Reproductive Health Research, World Health Organization, Geneva, 2012.

[11] Institute for Reproductive Health \& Georgetown University. Counseling Clients in the Standard Days Method: A Training for Service Providers, Georgetown University, Washington: Institute for Reproductive Health, 2005.

[12] International Planned Parenthood Federation. Programme Guidance on Counselling for STI/HIV Prevention in Sexual and Reproductive Health Settings, International Planned Parenthood Federation, London, 2002.

[13] Population council \& U.S. Agency for International Development. Improving Quality of Care for Family 
Planning Services in Uganda, Population counsel \& USAID, Kampala, 2003.

[14] J. Adinma, L. Ikeako, E. Adinma, C. Ezeama, J. Ugboaja. Awareness and Practice of Post Abortion Care Services among Health Care Professionals in southeastern Nigeria. Southeast Asian J Trop Med Public Health, Vol.41, No.3, 696- 704, 2010.

[15] S. Karvande, D. Sonawane, J. Samal, N. Mistry. Family Planning Training Needs of Auxiliary Nurse Midwives in Jkarkgand, India: Lesson from an Assessment. The National Medical Journal of India, Vol.31, No.2, 73-78, 2018.

[16] Y. Abebaw, S. Berhe, S. M. Abebe, M. Adefris, A. Gebeyehu, T. Gure, B. Asmare, M. Egziabher. Providers' knowledge on postpartum intrauterine contraceptive device (PPIUCD) service provision in Amhara region public health facility, Ethiopia. PLOS ONE, Vol.14, No.4, 1-15, 2019.

[17] T. Kebalepile. An Evaluation of the Quality of Care Midwives Provide during the Postpartum Period in Northern Botswana. University of Oslo, 1-131, 2001.

[18] S. Kamhawi, C. Underwood, H. Murad, B. Jabre. Client-centered counseling improves client satisfaction with family planning visits: Evidence from Irbid, Jordan. Glob Health Sci Pract, Vol.1, No.2, 180-192, 2013.

[19] E. Nasr, H. Hassan. Association between quality of family planning services and client's satisfaction level in maternal and child health centers in Port Said city. Journal of Nursing Education and Practice, Vol.6, No.1, 85-99, 2016.

[20] W. Tseganeh. Assessment of Quality of Family Planning Services, Bahar-Dar Special Zone, Amhara Regional State. Addis Ababa University, 2-113, 2005.
[21] MJ. Saka, LA. Yahaya, AO. Saka. Counseling and client provider-interactions as related to family planning services in Nigeria. J Educ Pract, Vol.3, No.5, 16-24, 2012.

[22] A. Shahidzadeh-Mahani, S. Omidvari, H. Baradaran, S. Azin. Factors affecting quality of care in family planning clinics: A study from Iran. International Journal for Quality in Health Care, Vol.20, No.4, 284-290, 2008.

[23] BT. Basavanthappa. Community Health Nursing (2nd ed.), Jaypee Publishers, New Delhi, 2008.

[24] M. Tuoane, NJ. Madise, I. Diamond. Provision of Family Planning Services in Lesotho. Guttmacher Institute, Vol.30, No.2, 9, 2004.

[25] Statistic Central Office. Famil health survey in Syrian Arab Republic: basic report about Syrian families, Statistic Central Office, Damascus, 2011. [In Arabic]

[26] A. Abdulsalam. How quality of care in the field of family planning affects contraception use among Syrian women?. Damascus University J of health sciences, Vol.25, No.2, 11-28, 2009. [In Arabic]

[27] M. Atuahene, E. Afari, M. Adjuik, S. Obed. Health knowledge, attitudes and practices of family planning service providers and clients in Akwapim North District of Ghana. Contraception and Reproductive Medicine, Vol.1, No.5, 1-8, 2016.

[28] R. Rahmati, T. Khadivzadeh, H. Esmaily, H. Bahrami. Evaluation of the performance of the health care workers in giving fertility counseling. Journal of Midwifery \& Reproductive Health, Vol.5, No.2, 911-918, 2017. 